\title{
Relationship Between Parents’ Report Rate of Twin Language and Factors Related to Linguistic Development: Older Sibling, Nonverbal Play and Preschool Attendance
}

\author{
Chisato Hayashi,' Kazuo Hayakawa, ' Chika Tsuboi, ${ }^{2}$ Keiko Oda, ${ }^{3}$ Yukiko Amau, ${ }^{4}$ Yoko Kobayashi, ${ }^{1}$ \\ and Kenji Kato ${ }^{5}$ \\ ' Department of Health Promotion Science, Faculty of Health Sciences, Graduate School of Medicine, Osaka University, Osaka, Japan \\ ${ }^{2}$ Division of Health Management, Canon Co., Osaka City, Japan \\ ${ }^{3}$ Nishinomiya City Hospital, Nishinomiya City, Japan \\ ${ }^{4}$ Twin Mothers' Club, Tokyo, Japan \\ ${ }^{5}$ Department of Medical Epidemiology \& Biostatistics, The Karolinska Institute, Stockholm, Sweden
}

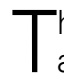
he definition and nature of twin language has been a focus of recent studies concerned with the phenomenon. There has been a call for a tighter definition and understanding of the meaning of twin language (Thorpe et al., 2001). This article sought to identify social factors associated with the parent report of twin language and thus provide further understanding of the phenomenon. Data from 583 mothers of twins aged 25 to 59 months were analyzed using multiple logistic regression. Factors included in the modeling of parentreport twin language included social experience factors such as presence of siblings, attendance at preschool education and reports of nonverbal play. It was found that twin pairs who didn't have an older sibling, who showed frequent nonverbal play and who didn't attend preschool were more likely to have a twin language. Moreover, in the group not having an older sibling, the influence of whether twins attended preschool or not was strong and the odds ratio was 0.589 (95\% confidence intervals $0.360-0.963)$. The findings suggest that social experience factors are important predictors of the parent reporting of twin language.
\end{abstract}

Numerous previous studies have reported that the language development of twins is delayed in comparison with that of singletons (Conway et al., 1980; Day, 1932; Lytton et al., 1977; Mittler, 1970; Savic, 1980; Tomasello et al., 1986). Rutter et al. (2003) found that at 3 years old, the language lag was 3.1 months, a difference of about half a standard deviation, in a large-scale epidemiological study. In addition, Dale et al. (1998) reported that at 2 years old, twins were about 3.5 months behind on average, compared to a United States sample of singletons.

One possible explanation for language delay is that twin children have a separate form of communication which interferes with normal language development. This separate form of communication has been variously termed autonomous speech (Bakker, 1987; Luria \& Yudovich, 1966), secret language (Hay et al., 1987; Mittler, 1970), criptophasia (Savic, 1980) and twin language (Bishop \& Bishop, 1998; Bishop et al., 1999; Dodd \& McEvoy, 1994; Hayashi \& Hayakawa, 2004). Reports of twin language have taken two forms, namely case studies and parent report studies.

There have been a number of case studies of specific examples of unusual communication between twin pairs. For example, in 1932, Day reported a case of a pair of twin boys living in Boston in 1860 who developed a twin language very unlike English (Day, 1932). Luria and Yudovich (1966) conducted a longterm observational study of a pair of identical twins aged 5 years. These twins exhibited complex phonetic impairment and had primitive speech - so-called autonomous speech - which does not possess the developed system of normal language. Bakker (1987) later compared the nine autonomous languages described in the literature, and reported that the words of the autonomous languages were imitations of words from the parents' language or sound imitations. In addition, the grammar can be considered as differing in many respects from the language of the parents.

There have been a number of studies which use parent report of twin language. For example, Mittler (1970) asked parents to report if their twins had secret language and found that $47 \%$ of the sample of 200 parents of twin reported this to be the case. Similarly Hay et al. (1987) found that parents of male

Received 2 September, 2004; accepted 11 October, 2005.

Address for correspondence: Chisato Hayashi, Department of Health Promotion Science, Faculty of Health Sciences, Graduate School of Medicine, Osaka University, 1-7 Yamadaoka, Suita City, Osaka 5650871, Japan.E-mail: chisato@sahs.med.osaka-u.ac.jp 


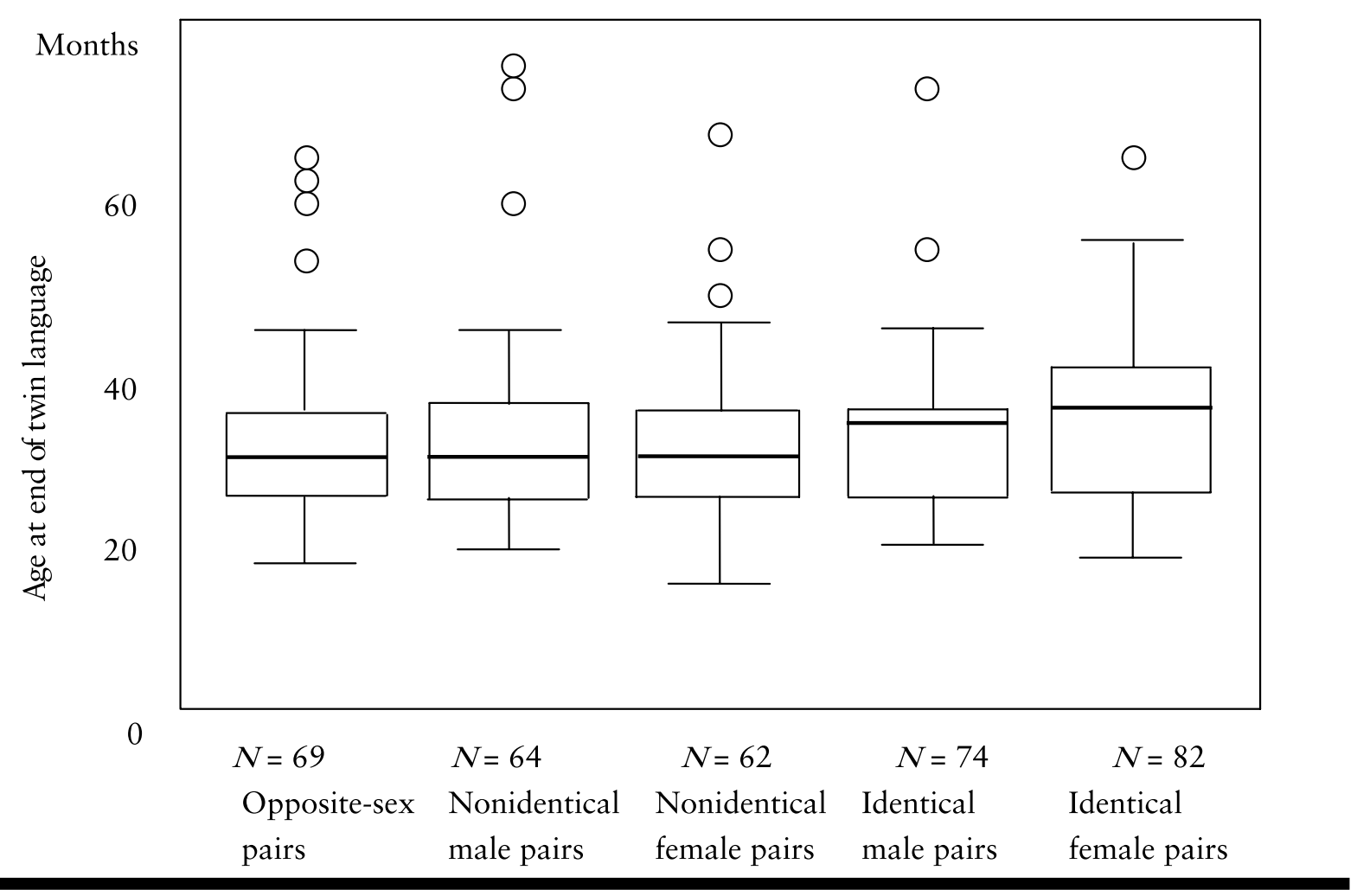

Figure 1

Median, 1st and 3rd quartiles, minimum and maximum of age at having twin language.

twin pairs reported a higher rate of secret language than those of female twin pairs.

One criticism of earlier studies using parent report is that the definition of twin or secret language was not given. As a result, parents were left to determine their own understanding of the phenomenon and may have been reporting on a range of language phenomena. More recent parent report studies have provided definitions of language phenomena and avoided the use of terms such as 'secret' or 'twin' language (Bishop et al., 1999; Thorpe et al., 2001). Thorpe et al. (2001) attempted to improve the method of obtaining data from parental reporting through asking parents to give detailed accounts of their children's communication. As a result, they defined two separate language phenomena which might be termed twin language: private language which is a form of communication used exclusively within the child pair that was intelligible to the pair and not used with others, and shared understanding which was defined as a spoken communication that was not intelligible to others and was not directed exclusively to the other child in the pair (it was also used in communication with parents and siblings even if they found it unintelligible). Some researchers suggested that twin language is no more than immature speech forms or phonologically disordered speech (Bishop \& Bishop, 1998; Dodd \& McEvoy, 1994; Savic, 1980). Shared language as defined by Thorpe and colleagues would fit with this notion. The twin children appear to have a secret language because they can understand each other better, probably because they share a social world.

Rather less research has attempted to examine the factors associated with reporting of twin language. Dodd and McEvoy (1994) pointed out that multiplebirth children are left to play with each other more than a singleton would be left to play with a child of the same age, and therefore, they interact in a play situation with another child of a similar developmental level. This experience may increase understanding of a co-twin but limit opportunity to utilize language and gain language skills with others. There is a need to examine social experiences which may relate to the reported presence of twin language.

In this study, we focused on the relationship between social experience predictors related to the twin situation and twin language. Social experience predictors include whether the twins are identical or not, nonverbal play, and environmental factors related to linguistic development, such as number of household members (an older sibling, younger sibling and grandparents) and preschool attendance. The purpose of this article was to clarify which social predictors affect the parents' reports of twin language.

\section{Methods}

Definition of Terms

Twin language is defined as a language that is unique to each pair of twins and cannot be understood by either 


\begin{tabular}{|c|c|c|}
\hline \multicolumn{3}{|c|}{ Demographics of Parents' Report Rate of Twin Language } \\
\hline & \multicolumn{2}{|c|}{ Parents' report rate of twin language } \\
\hline & $\begin{array}{c}\text { Yes } \\
n(\%)\end{array}$ & $\begin{array}{c}\text { No } \\
n(\%)\end{array}$ \\
\hline $\begin{array}{l}\text { Total sample } \\
\qquad(n=580: 100 \%)\end{array}$ & $282(48.6)$ & $298(51.4)$ \\
\hline $\begin{array}{c}\text { Opposite-sex pairs } \\
\quad(n=158: 27.2 \%)\end{array}$ & $77(48.7)$ & $81(51.3)$ \\
\hline \multicolumn{3}{|c|}{ Nonidentical pairs of same sex } \\
\hline $\begin{array}{l}\text { Male } \\
\qquad(n=123: 21.2 \%)\end{array}$ & $56(45.5)$ & $67(54.5)$ \\
\hline $\begin{array}{l}\text { Female } \\
\qquad(n=122: 21.0 \%)\end{array}$ & $49(40.2)$ & $73(59.8)$ \\
\hline \multicolumn{3}{|l|}{ Identical pairs } \\
\hline $\begin{array}{l}\text { Male } \\
\qquad(n=81: 14.0 \%)\end{array}$ & $44(54.3)$ & $37(45.7)$ \\
\hline $\begin{array}{l}\text { Female } \\
\qquad(n=96: 16.6 \%)\end{array}$ & $56(58.3)$ & 40 (41.7) \\
\hline
\end{tabular}

their mother or others. In addition, we defined twin language as a language that was used in specific situations only (during play, meals, etc.) in twins. The mother was asked whether the twins used an original language that could not be understood by either their mother or others.

Nonverbal play is defined as play that does not involve language (e.g., building with blocks, drawing pictures). The mother was asked whether the twin pair frequently showed nonverbal play or not.

\section{Study Population}

Questionnaires were sent to 2733 members of the Twin Mothers' Club (the Japanese Mothers' Organization for Twin and Higher Order Multiple Births) and recruited participants, and 1428 (52\%) responded to the questionnaire in 1999. Fourteen pairs of twins were excluded from this study because of cerebral palsy, cleft palate, autism or Down's syndrome, to remove influential outliers. Moreover, in order to understand each other, not only expression of sounds but also perception of sounds is necessary. Twins under the age of 6 months were considered unable to use twin language, and the 19 pairs of twins for which the age of first twin language was reported to be less than 6 months were therefore excluded from this study. In addition, to reduce the effect of mothers' recall bias, only twins aged 25 to 59 months ( 2 to 4 years old) were analyzed in this study as the twins' maximum age for parents' report rate of twin language was 59 months in a box-and-whisker plot (Figure 1). The final sample consisted of 583 respondents.

The question 'whether the twins are as alike as two peas in a pod' was used for zygosity classification. Twin pairs for which the answer to this question was 'Yes' were determined to be identical, and twin pairs for which the answer was 'No' were determined to be nonidentical. Previous studies reported that more than
$90 \%$ of twins were diagnosed correctly using these criteria (Hayakawa et al., 1985; Ooki et al., 1990; Ooki et al., 1989). Thirteen pairs were excluded from this study because it was not possible to determine whether they were exactly alike. The results of classification were 158 nonidentical opposite-sex pairs $(27.2 \%), 123$ nonidentical male pairs $(21.2 \%), 122$ nonidentical female pairs $(21.0 \%), 81$ identical male pairs $(14.0 \%)$ and 96 identical female pairs $(16.6 \%$; Table 1$)$.

\section{Questionnaire}

The core questionnaire asked for data on birthweight (g), age at first spoken word (months), whether the twins were as alike as two peas in a pod ('yes'/'no'), whether the twins had an original language that could not be understood by either their mother or others ('yes'/'no'), if yes, whether the twin language was words or sentences, the situations in which the twins used twin language, age at first spoken unique language between twins and duration (months), household members (people), type of home (apartment or detached house), whether the twin pair attended preschool ('yes'/'no'), whether the twin pair frequently showed nonverbal play (play that does not involve language, e.g., building with blocks, drawing a picture; 'yes'/'no'), and whether twin pair had neighborhood friends ('yes'/'no'; see the Appendix for items, questionnaire and coding).

\section{Statistical Analysis}

First, logistic regression analysis was used to determine the significance of group differences, according to whether the twin pair was exactly alike or not in the parents' report rate of twin language and 12 variables related to linguistic development. Second, nine nested logistic regression models were estimated to examine the independent effects on the dependent variables. In Model 1, we began by showing the relationships between parents' report rate of twin language and whether the twin pair was identical or not, controlling for the twins' age. In Model 2, nonverbal play was added as an independent variable. In addition, older sibling (Model 3), preschool attendance (Model 4), both nonverbal play and older sibling (Model 5), both older sibling and preschool attendance (Model 6), both nonverbal play and preschool attendance (Model 7), and nonverbal play, older sibling and preschool attendance (Model 8) were added as independent variables. Lastly, younger sibling, living with grandparents, and disease or handicap of twin were included in Model 9 as independent variables. Third, multivariate ordered logistic regression models were used to consider the difference in the influence of having an older sibling in identical pairs and nonidentical pairs. Ordered logistic regression was performed to obtain the odds ratio (OR) of the parents' report rate of twin language among the five groups defined by whether the twin pair was exactly alike or not.

ORs and $95 \%$ confidence intervals (CI) for unit changes in each factor were computed. All $p$ values 
Table 2

Characteristics of Twin Language

Twin language as words or sentences

\begin{tabular}{lc}
\hline Words & $N=76(27.7 \%)$ \\
Sentences & $N=198(72.3 \%)$ \\
& mean age \pm standard deviation $=43.7 \pm 9.5$ (months) \\
& mean age \pm standard deviation $=38.3 \pm 9.2$ (months) \\
\hline
\end{tabular}

Situation in which twins used twin language (multiple answers)

\begin{tabular}{ll}
\hline During play & $N=275$ \\
Before sleep in bed & $N=9$ \\
Always & $N=8$ \\
During meals & $N=2$ \\
\hline
\end{tabular}

presented are two-sided, and the 5\% significance level was used in the statistical tests.

\section{Results}

The characteristics of the study population are summarized in Table 1 . The sample of this study consisted of 158 opposite-sex pairs $(27.2 \%), 123$ nonidentical male pairs $(21.1 \%), 122$ nonidentical female pairs $(21.0 \%), 81$ identical male pairs $(14.0 \%)$ and 96 identical female pairs $(16.6 \%)$. Of the 580 pairs, 282 pairs
$(48.6 \%)$ exhibited a twin language. The percentage parents' report of a twin language was highest in identical female pairs $(58.3 \%)$, and was lowest in nonidentical female pairs $(40.2 \%)$.

Table 2 shows the characteristics of twin language. Seventy-six pairs $(27.7 \%)$ used twin language as words, whereas 198 pairs $(72.3 \%)$ used twin language as sentences. The age of the group using twin language as words was 43.7 months (mean, $S D=9.5$ ). On the other hand, the age of the group using twin language as sentences was 38.3 months (mean, $S D=9.2$ ). That is, the group using twin language as sentences was younger than the group using twin language as words. In addition, regarding the situation in which twins used twin language, during play was the most frequent $(N=275)$, followed by in bed before going to sleep in nine pairs, at all times in eight pairs, and during meals in two pairs.

Table 3 shows descriptive statistics (mean, standard deviation, variance, median, mode, 1 st and 3rd quartiles, minimum and maximum) for the 14 variables related to language development (age of mother, length of gestation, time of weaning, body length at birth, body height at 18 months, bodyweight at birth, bodyweight at 18 months, age of first walking, age of first tooth, age of first spoken word, age at start of twin language, age at end of twin language, duration of twin language, and situation with the highest frequency of twin language).

Table 3

Descriptive Statistics for Variables Related to Language Development

\begin{tabular}{|c|c|c|c|c|c|c|c|c|c|}
\hline & $N$ & Mean & $S D$ & Median & Mode & 1 st and & Brd quartiles & Minimum & Maximum \\
\hline Age of mother (years) & 576 & 34.1 & 3.6 & 34.0 & 34.0 & $(32.0$ & $36.0)$ & 24.0 & 44.0 \\
\hline Age of twin (months) & 583 & 42.6 & 9.8 & 43.0 & 37.0 & $(34.0$ & $51.0)$ & 25.0 & 59.0 \\
\hline Length of gestation (weeks) & 562 & 36.9 & 2.2 & 37.2 & 37.0 & $(36.1$ & 38.2) & 26.1 & 41.6 \\
\hline Time of weaning (months) & 561 & 13.7 & 4.9 & 12.0 & 12.0 & $(12.0$ & 15.0) & 1.0 & 36.0 \\
\hline \multirow[t]{2}{*}{ Body length at birth $(\mathrm{cm})$} & 569 & 45.8 & 3.0 & 46.0 & 48.0 & $(44.2$ & 48.0) & 29.0 & 52.5 \\
\hline & 561 & 45.5 & 3.2 & 46.0 & 45.0 & $(44.0$ & 47.5) & 27.0 & 51.5 \\
\hline \multirow[t]{2}{*}{ Body height at 18 months $(\mathrm{cm})$} & 554 & 79.3 & 4.6 & 79.8 & 82.0 & $(77.7$ & 81.6) & 44.0 & 88.0 \\
\hline & 554 & 79.1 & 4.6 & 79.7 & 80.0 & (77.5 & 81.5) & 40.5 & 88.8 \\
\hline \multirow[t]{2}{*}{ Bodyweight at birth (g) } & 580 & 2376.7 & 443.7 & 2402.0 & 2158.0 & $(2146.5$ & 2657.5) & 834.0 & 3634.0 \\
\hline & 581 & 2306.9 & 457.4 & 2336.0 & 2300.0 & (2039.0 & 2593.0) & 670.0 & 3660.0 \\
\hline \multirow[t]{2}{*}{ Bodyweight at 18 months (g) } & 556 & $10,244.0$ & 1220.4 & $10,300.0$ & $10,000.0$ & $(9600.0$ & $11,000.0)$ & 1010.0 & $13,800.0$ \\
\hline & 555 & $10,119.4$ & 1227.6 & $10,100.0$ & $11,000.0$ & $(9450.0$ & $10,900.0)$ & 1434.0 & $13,600.0$ \\
\hline \multirow[t]{2}{*}{ Age of first walking (months) } & 574 & 12.8 & 2.4 & 13.0 & 12.0 & $(11.0$ & 14.0) & 8.0 & 32.0 \\
\hline & 574 & 12.8 & 2.4 & 12.0 & 12.0 & $(11.0$ & 14.0) & 8.0 & 27.0 \\
\hline \multirow[t]{2}{*}{ Age of first tooth (months) } & 538 & 7.5 & 2.3 & 7.0 & 7.0 & 16.0 & $9.0)$ & 0.0 & 20.0 \\
\hline & 537 & 7.6 & 3.5 & 7.0 & 7.0 & 16.0 & $8.0)$ & 0.0 & 70.0 \\
\hline \multirow[t]{2}{*}{ Age of first spoken word (months) } & 492 & 13.5 & 5.0 & 13.0 & 12.0 & $(11.0$ & $16.0)$ & 3.0 & 42.0 \\
\hline & 484 & 14.3 & 4.7 & 14.0 & 12.0 & $(11.0$ & 17.0) & 3.0 & 43.0 \\
\hline Age at start of twin language (months) & 236 & 22.5 & 7.7 & 24.0 & 24.0 & $(18.0$ & 26.8) & 6.0 & 49.0 \\
\hline Age at end of twin language (months) & 116 & 30.3 & 7.3 & 30.0 & 24.0 & $(24.0$ & $36.0)$ & 15.0 & 54.0 \\
\hline Duration of twin language (months) & 109 & 10.5 & 5.3 & 10.0 & 12.0 & 16.0 & 12.0) & 2.0 & 30.0 \\
\hline $\begin{array}{l}\text { Age of the highest frequency of twin } \\
\text { language (months) }\end{array}$ & 221 & 28.3 & 8.6 & 27.0 & 27.0 & $(24.0$ & $34.0)$ & 3.0 & 54.0 \\
\hline
\end{tabular}


Table 4

Crude Odds Ratio and 95\% Confidence Intervals for Association of Environmental Factors and Twin Language

\begin{tabular}{|c|c|c|}
\hline \multirow[b]{2}{*}{ Opposite-sex pairs ( $N=158$ ) } & \multicolumn{2}{|c|}{$\begin{array}{l}\text { Parents' report rate } \\
\text { of 'twin language' }\end{array}$} \\
\hline & 1 & \\
\hline Nonidentical male pairs ( $N=123$ ) & $0.892(0.555-1.436)$ & $p=.639$ \\
\hline Nonidentical female pairs ( $N=122$ ) & $0.717(0.443-1.159)$ & $p=.175$ \\
\hline Identical male pairs $(N=81)$ & $1.270(0.740-2.179)$ & $p=.386$ \\
\hline Identical female pairs ( $N=96$ ) & $1.495(0.893-2.501)$ & $p=.126$ \\
\hline \multicolumn{3}{|l|}{ Disease or handicap of twins } \\
\hline Yes $(n=171)$ & $1.137(0.795-1.624)$ & $p=.482$ \\
\hline No $(n=412)$ & 1 & \\
\hline \multicolumn{3}{|l|}{ Mother with job } \\
\hline Yes $(n=64)$ & $1.338(0.790-2.264)$ & $p=.279$ \\
\hline No $(n=499)$ & 1 & \\
\hline \multicolumn{3}{|l|}{ Nonverbal play } \\
\hline Yes $(n=160)$ & $1.871(1.289-2.716)$ & $p=.001^{* *}$ \\
\hline No $(n=402)$ & 1 & \\
\hline \multicolumn{3}{|l|}{ Type of house } \\
\hline Detached house $(n=262)$ & $0.763(0.549-1.060)$ & $p=.106$ \\
\hline Apartment $(n=319)$ & 1 & \\
\hline \multicolumn{3}{|l|}{ Preschool attendance } \\
\hline Yes $(n=150)$ & $0.645(0.442-0.942)$ & $p=.023^{*}$ \\
\hline No $(n=432)$ & 1 & \\
\hline \multicolumn{3}{|l|}{ Neighborhood friends } \\
\hline Yes $(n=279)$ & $1.260(0.909-1.748)$ & $p=.166$ \\
\hline No $(n=301)$ & 1 & \\
\hline \multicolumn{3}{|l|}{ Older sibling } \\
\hline Yes $(n=194)$ & $0.619(0.436-0.878)$ & $p=.007^{* *}$ \\
\hline No $(n=386)$ & 1 & \\
\hline \multicolumn{3}{|l|}{ Younger sibling } \\
\hline Yes $(n=41)$ & $1.061(0.558-2.018)$ & $p=.856$ \\
\hline No $(n=539)$ & 1 & \\
\hline \multicolumn{3}{|l|}{ Living with grandparents } \\
\hline Yes $(n=108)$ & $0.793(0.520-1.210)$ & $p=.283$ \\
\hline No $(n=472)$ & 1 & \\
\hline
\end{tabular}

Table 4 presents the results of logistic regression analysis for each categorical variable, to study the association between variables related to linguistic development and the parents' report rate of twin language. Logistic regression analysis of the parents' report rate of twin language as the dependent variable, and whether the twin pair was identical or not, and variables related to linguistic development as independent variables, was used. As seen in this table, nonverbal play, older sibling and preschool attendance were found to be significant in the parents' report rate of twin language.

To assess the underlying associations among study variables, bivariate correlations were examined, and the results are presented in Table 5. A mother with a job was strongly associated with preschool attendance $(r=.531)$.
On the other hand, the type of house was highly associated with living with grandparents $(r=.500)$. The strong associations (mother with a job and preschool attendance; type of house and living with grandparents) were not surprising, as twins of mothers with jobs more often attended preschool and twins who lived with grandparents had a larger house (a detached house rather than an apartment). Therefore, these two variables (mother with a job and type of house) were excluded from the logistic model to reduce confounding factors. All other correlation coefficients were below .300 .

Table 6 presents the results of logistic analysis for parents' report rate of twin language and variables related to linguistic development. In the first model, sex, whether the twin pair was exactly alike or not, and twins' age were included. Nonverbal play was then added as an independent variable in the second (Model 2 ), followed by older sibling in the third (Model 3), followed by preschool attendance in the fourth (Model 4). Model 2 revealed that nonverbal play was a strong positive predictor of parents' report rate of twin language (OR $=1.767 ; 95 \%$ CI 1.196-2.609). Model 3 indicated that having an older sibling was a strong negative predictor of parents' report rate of twin language $(\mathrm{OR}=0.575 ; 95 \%$ CI $0.401-0.825)$. Model 4 revealed that preschool attendance was a strong negative predictor of parents' report rate of twin language $(\mathrm{OR}=0.632$; 95\% CI 0.431-0.928). Model 5 introduced both nonverbal play and older sibling as independent variables, followed by both older sibling and preschool attendance in Model 6, followed by both nonverbal play and preschool attendance in Model 7. In all three models, nonverbal play was a significant positive predictor of parents' report rate of twin language, and older sibling and preschool attendance were significant negative predictors.

The results of Model 8 showed that nonverbal play, older sibling and preschool attendance were negatively associated with parents' report rate of twin language. In other words, twins who frequently exhibited nonverbal play were about 1.8 times more likely to have a twin language than those who did not frequently exhibit nonverbal play. In addition, twins who had an older sibling were about 0.6 times more likely to have a twin language than those who did not have an older sibling. Twins who attended preschool were about 0.6 times more likely to have a twin language than those who did not attend preschool. These variables were significantly associated with the parents' report rate of twin language, even when the model included a younger sibling, living with grandparents, and disease or handicap of a twin (Model 9).

Next, the influence of having an older sibling was considered. First, as shown in Table 7, there were 43 pairs $(27.4 \%)$ of opposite-sex pairs who had an older sibling and 114 pairs $(72.6 \%)$ who did not. Second, in nonidentical male pairs, 40 pairs $(32.5 \%)$ had an older sibling and 83 pairs $(67.5 \%)$ did not. Third, in nonidentical female pairs, 36 pairs $(29.3 \%)$ had an 
Table 5

Correlation Matrix of Study Variables

\begin{tabular}{|c|c|c|c|c|c|c|c|c|c|c|c|c|c|c|c|}
\hline & & 1 & 2 & 3 & 4 & 5 & 6 & 7 & 8 & 9 & 10 & 11 & 12 & 13 & 14 \\
\hline 1 & Nonidentical male pairs & 1.000 & & & & & & & & & & & & & \\
\hline 2 & Nonidentical female pairs & $.272^{* *}$ & 1.000 & & & & & & & & & & & & \\
\hline 3 & Identical male pairs & $.211^{* *}$ & $.210^{* *}$ & 1.000 & & & & & & & & & & & \\
\hline 4 & Identical female pairs & $.234^{* *}$ & $.233^{* *}$ & $.181^{* *}$ & 1.000 & & & & & & & & & & \\
\hline 5 & Twins' age & .024 & .020 & .055 & .057 & 1.000 & & & & & & & & & \\
\hline 6 & Nonverbal play & .079 & $.131^{* *}$ & .066 & .044 & $.216^{* *}$ & 1.000 & & & & & & & & \\
\hline 7 & Older sibling & .012 & .047 & $.083^{*}$ & .077 & .073 & .037 & 1.000 & & & & & & & \\
\hline 8 & Preschool attendance & .017 & .019 & .045 & .010 & .001 & .015 & .015 & 1.000 & & & & & & \\
\hline 9 & Mother with job & .037 & .047 & .036 & .034 & .008 & .046 & .019 & $.531^{* *}$ & 1.000 & & & & & \\
\hline 10 & Younger sibling & .004 & .029 & .054 & .003 & .030 & .049 & .053 & .037 & .009 & 1.000 & & & & \\
\hline 11 & Living with grandparents & .047 & .014 & .025 & .044 & .008 & .006 & $.102^{*}$ & .031 & .018 & .024 & 1.000 & & & \\
\hline 12 & Type of house & .006 & .004 & .014 & .031 & .065 & .048 & $.145^{* *}$ & .070 & $.109^{* *}$ & .021 & $.500^{* *}$ & 1.000 & & \\
\hline 13 & Disease or handicap of twin & .080 & .056 & .008 & .022 & .005 & .029 & .022 & $.086^{*}$ & .035 & .046 & .045 & .007 & 1.000 & \\
\hline 14 & Appearance of twin language & .031 & $.087^{*}$ & .047 & $.088^{*}$ & .050 & $.140^{* *}$ & $.112^{* *}$ & $.095^{*}$ & .046 & .008 & .045 & .067 & .029 & 1.000 \\
\hline
\end{tabular}

Note: ${ }^{*} p<.05 ;{ }^{* *} p<.01$.

older sibling and 87 pairs $(70.7 \%)$ did not. Fourth, in identical male pairs, 35 pairs $(43.2 \%)$ had an older sibling and 46 pairs $(56.8 \%)$ did not. Lastly, in nonidentical female pairs, 40 pairs $(41.7 \%)$ had an older sibling and 56 pairs $(58.3 \%)$ did not. The research question is whether identical pairs are more likely to have a twin language than nonidentical pairs, and on the other hand, whether identical pairs are less likely to have an older sibling than nonidentical pairs. As shown in our preceding study, twins who had an older sibling were significantly more likely to have a twin language. To investigate whether the parents' report rate of twin language in identical pairs is controlled by the difference that identical pairs are more likely to have an older sibling than nonidentical pairs, multiple logistic regression analysis was performed separately in the group that had an older sibling and the group that did not. As shown in Table 8, for the group with an older sibling, whether the twin pair was identical or not was no longer significant, and only nonverbal play was significant $(p=.005 ;$ OR $=2.790 ; 95 \%$ CI $1.369-5.685)$. In the group that did not have an older sibling, on the other hand, whether the twin pair was identical or not was significant, $\mathrm{OR}=0.978$ for nonidentical male pairs (95\% CI 0.536-1.785), 0.851 for nonidentical female pairs (95\% CI $0.470-1.540), 1.611$ for identical male pairs $(95 \%$ CI $0.771-3.365)$ and 2.135 for identical female pairs (95\% CI 1.060-4.302; $p=.034$ ).

\section{$\overline{\text { Discussion }}$}

This study shows that frequent nonverbal play, having an older sibling and preschool attendance independently predict the parent reporting of twin language. Twin pairs that have an older sibling or who attended preschool were significantly less likely to be reported as having a twin language, whereas those who engaged in high frequency nonverbal play were more likely to be reported as having a twin language. Whether the twin pair was identical or not did not independently predict the reporting of twin language. Lastly, in the group that did not have an older sibling it was found that identical female pairs and preschool attendance predicted reporting. In the absence of an older sibling, being identical female twins increased the likelihood of reporting of twin language, whereas attendance at preschool reduced this likelihood.

The data indicated an association between social experience and parent reporting of twin language. Those variables associated with exposure to a wider social environment outside the bond of the twin pair, particularly attendance at preschool and presence of an older sibling, were those predicting lower reports of twin language. In this study, a broad definition of twin language was adopted (one that was not limited exclusively to language between the pair). It is therefore likely that the findings reflect the impact of social environment on clarity of speech. Dodd and McEvoy (1994) suggest that much parent-defined twin language is, in fact, immature speech. The presence of older siblings and attendance at preschool may promote language development and commensurately decrease reports of twin language. In the case of an older sibling, Thorpe et al. (2003) suggested the possibility that the presence of an older sibling would make the family situation more similar to that of a singleton. The older sibling not only provides a more sophisticated model of language themselves but also influences the level of language used by parents to which the younger child is exposed. In the case of preschool attendance, Luria and Yudovich (1966) removed the 'twin situation' by separating the children and placing them in separate, parallel groups in a kindergarten and then observing the changes that took place. As a result, substantial improvements in the twins' speech were 
Table 6

Multiple Logistic Analysis for Independent Predictors of Twin Language

\begin{tabular}{|c|c|c|c|c|c|c|}
\hline Variable & Multivariate odds ratio & & Multivariate odds ratio & & Multivariate odds rati & \\
\hline & $(95 \% \mathrm{Cl})$ & $p$ value & $(95 \% \mathrm{Cl})$ & $p$ value & $(95 \% \mathrm{Cl})$ & $p$ value \\
\hline & Model 1 & & Model 2 & & Model 3 & \\
\hline Opposite-sex pairs & 1 & & 1 & & 1 & \\
\hline \multicolumn{7}{|l|}{ Nonidentical pairs of same sex } \\
\hline Male & $0.896(0.556-1.444)$ & .652 & $0.866(0.528-1.420)$ & .568 & $0.889(0.548-1.442)$ & .634 \\
\hline Female & $0.720(0.444-1.166)$ & .181 & $0.741(0.449-1.224)$ & .242 & $0.714(0.439-1.162)$ & .175 \\
\hline \multicolumn{7}{|l|}{ Identical pairs } \\
\hline Male & $1.308(0.760-2.251)$ & .332 & $1.219(0.698-2.128)$ & 487 & $1.411(0.814-2.447)$ & .220 \\
\hline Female & $1.539(0.917-2.583)$ & .102 & $1.510(0.885-2.575)$ & .131 & $1.654(0.977-2.801)$ & .061 \\
\hline Twins' age & $0.987(0.970-1.004)$ & .121 & $0.992(0.975-1.010)$ & .377 & $0.987(0.970-1.004)$ & .140 \\
\hline Nonverbal play & & & $1.767(1.196-2.609)$ & $.004^{* *}$ & & \\
\hline Older sibling & & & & & $0.575(0.401-0.825)$ & $.003^{* *}$ \\
\hline \multicolumn{7}{|l|}{ Preschool attendance } \\
\hline & Model 4 & & Model 5 & & Model 6 & \\
\hline Opposite-sex pairs & 1 & & 1 & & 1 & \\
\hline \multicolumn{7}{|l|}{ Nonidentical pairs of same sex } \\
\hline Male & $0.906(0.561-1.464)$ & .688 & $0.864(0.523-1.428)$ & .570 & $0.900(0.554-1.463)$ & .671 \\
\hline Female & $0.717(0.442-1.163)$ & .178 & $0.731(0.441-1.212)$ & .224 & $0.711(0.436-1.158)$ & .171 \\
\hline \multicolumn{7}{|l|}{ Identical pairs } \\
\hline Male & $1.353(0.783-2.337)$ & .278 & $1.324(0.751-2.332)$ & .332 & $1.459(0.838-2.541)$ & .182 \\
\hline Female & $1.553(0.923-2.613)$ & .098 & $1.634(0.948-2.814)$ & .077 & $1.668(0.982-2.832)$ & .058 \\
\hline Twins' age & $0.986(0.970-1.003)$ & .117 & $0.992(0.975-1.010)$ & .408 & $0.987(0.970-1.004)$ & .135 \\
\hline Nonverbal play & & & $1.740(1.174-2.578)$ & $.006^{* *}$ & & \\
\hline Older sibling & & & $0.567(0.391-0.821)$ & $.003^{* *}$ & $0.576(0.401-0.827)$ & $.003^{* *}$ \\
\hline \multirow[t]{2}{*}{ Preschool attendance } & $0.632(0.431-0.928)$ & $.019 *$ & & & $0.633(0.430-0.932)$ & $.021^{*}$ \\
\hline & Model 7 & & Model 8 & & Model 9 & \\
\hline Opposite-sex pairs & 1 & & 1 & & 1 & \\
\hline \multicolumn{7}{|l|}{ Nonidentical pairs of same sex } \\
\hline Male & $0.869(0.528-1.429)$ & .580 & $0.868(0.524-1.437)$ & .582 & $0.868(0.523-1.441)$ & .585 \\
\hline Female & $0.732(0.443-1.212)$ & .225 & $0.722(0.435-1.200)$ & .209 & $0.739(0.444-1.232)$ & .247 \\
\hline \multicolumn{7}{|l|}{ Identical pairs } \\
\hline Male & $1.255(0.716-2.201)$ & .428 & $1.363(0.770-2.411)$ & .288 & $1.377(0.775-2.448)$ & .275 \\
\hline Female & $1.509(0.882-2.581)$ & .133 & $1.633(0.945-2.821)$ & .079 & $1.638(0.946-2.835)$ & .078 \\
\hline Twins' age & $0.992(0.974-1.010)$ & .380 & $0.992(0.975-1.011)$ & .415 & $0.992(0.975-1.011)$ & .410 \\
\hline Nonverbal play & 1.789 (1.209-2.649) & $.004^{* *}$ & $1.762(1.187-2.618)$ & $.005^{* *}$ & $1.771(1.191-2.635)$ & $.005^{* *}$ \\
\hline Older sibling & & & $0.569(0.392-0.825)$ & $.003^{* *}$ & $0.579(0.398-0.842)$ & $.004^{* *}$ \\
\hline Preschool attendance & $0.614(0.414-0.910)$ & $.015^{*}$ & $0.617(0.415-0.918)$ & $.017^{*}$ & $0.604(0.405-0.903)$ & $.014^{*}$ \\
\hline Younger sibling & & & & & $1.274(0.641-2.532)$ & .490 \\
\hline Living with grandparents & & & & & $0.817(0.522-1.277)$ & .375 \\
\hline Disease or handicap of twin & & & & & $1.217(0.830-1.784)$ & .315 \\
\hline
\end{tabular}

Note: ${ }^{*} p<.05 ;{ }^{* *} p<.01$.

observed just 3 months after the experiment began. They reported that in exceptional twin pairs' social intervention, encouraging interaction with peers and limiting communication with the co-twin 'created an objective necessity for speech communication', leading to improved language skills.

The finding that high frequency nonverbal play was associated with the higher reporting of twin language by parents would also fit with this explanation of the findings. Children whose play is characterized by the absence of verbal communication in the age range studied here are quite possibly language delayed. As the study is correlative, it is not possible to indicate the direction of association. It is likely, however, that nonverbal play is indexing general levels of verbal ability and social experience.

This study was limited by the broad definition of twin language provided in the questionnaire design so that the true meaning of twin language to parents cannot be known. Nevertheless, it provides a large 
Table 7

Demographics of Having Older Sibling

\begin{tabular}{lcc}
\hline & \multicolumn{2}{c}{ Having older sibling } \\
\hline & Yes & No \\
& $n(\%)$ & $n(\%)$ \\
\hline $\begin{array}{l}\text { Total sample } \\
(n=580: 100 \%)\end{array}$ & $194(33.4)$ & $386(66.6)$ \\
Opposite-sex pairs & & \\
$(n=157: 27.1 \%)$ & $43(27.4)$ & $114(72.6)$ \\
Nonidentical pairs of same sex & & $83(67.5)$ \\
$\quad$ Male $(n=123: 21.2 \%)$ & $40(32.5)$ & $87(70.7)$ \\
Female $(n=123: 21.2 \%)$ & $36(29.3)$ & \\
Identical pairs & & $46(56.8)$ \\
$\quad$ Male $(n=81: 14.0 \%)$ & $35(43.2)$ & $56(58.3)$ \\
Female $(n=96: 16.6 \%)$ & $40(41.7)$ &
\end{tabular}

sample and has indicated the importance of social exposure and social experience in twin children's language development.

\section{Acknowledgments}

This work was supported in part by the Twin Mothers' Club (the Japanese Mothers' Organization for Twin and Higher Order Multiple Births). We would like to thank the twins and their parents for their participation in the study. We also acknowledge helpful discussions with colleagues of our laboratory.

\section{References}

Bakker, P. (1987). Autonomous languages of twins. Acta Geneticae Medicae et Gemellologiae (Roma), 36, 233-238.
Bishop, D. V. M., \& Bishop, S. J. (1998). 'Twin language': A risk factor for language impairment? Journal of Speech, and Hearing Research, 41, 150-160.

Bishop, D. V. M., Bishop, S. J., Bright, P., James, C., Delaney, T., \& Tallal, P. (1999). Different origin of auditory and phonological processing problems in child with language impairment: Evidence from a twin study. Journal of Speech and Hearing Research, 42, 155-168.

Conway, D., Lytton, H., \& Pysh, F. (1980). Twin-singleton language differences. Canadian Journal of Behavioural Science, 12, 264-271.

Dale, P. S., Simmonoff, E., Bishop, D. V. M., Eley, T. C., Oliver, B., Price T. S., Purcell. S., Stevenson. J., \& Plomin, R. (1998). Genetic influence on language delay in twoyear-old children. Nature Neuroscience, 1, 324-328.

Day, E. J. (1932). The development of language in twins: A comparison of twins and single children. Child Development, 3, 179-199.

Dodd, B., \& McEvoy, S. (1994). Twin language or phonological disorder? Journal of Child Language, 21, 273-289.

Hay, D. A., Prior, M., Collett, S., \& Williams, M. (1987). Speech and language development in preschool twins. Acta Geneticae Medicae et Gemellologiae, 36, 213-223.

Hayakawa, K., Simizu, T., \& Kanemitsu, Y. (1985). Zygosity diagnosis of twins by questionnaire in middle age. Japanese Journal of Public Health, 33, 340-344.

Hayashi, C., \& Hayakawa, K. (2004). Factors affecting the appearance of 'twin language': An original language naturally developing within twin pairs. Environmental Health and Preventive Medicine, 9, 103-110.

\section{Table 8}

Multiple Logistic Analysis for Independent Predictors of Twin Language in Groups According to Whether a Twin Has an Older Sibling or Not

\begin{tabular}{lcccc}
\hline \multicolumn{1}{c}{ No } & \multicolumn{3}{c}{ Older sibling } \\
\hline & Multivariate OR (95\%CI) & $p$ value & Multivariate OR (95\%CI) & $p$ value \\
\hline Opposite-sex pairs & 1 & & 1 & .351 \\
\hline Nonidentical pairs of same sex & $0.978(0.536-1.785)$ & & & \\
$\quad$ Male & $0.851(0.470-1.540)$ & .593 & $0.634(0.243-1.652)$ & .232 \\
$\quad$ Female & & & $0.533(0.190-1.496)$ & \\
Identical pairs & $1.611(0.771-3.365)$ & .205 & $0.933(0.350-2.482)$ & .889 \\
$\quad$ Male & $2.135(1.060-4.302)$ & $.034^{*}$ & $1.061(0.413-2.726)$ & .903 \\
$\quad$ Female & $0.991(0.969-1.014)$ & .458 & $0.993(0.962-1.025)$ & .662 \\
Twins' age & $1.428(0.883-2.311)$ & .146 & $2.790(1.369-5.685)$ & $.005^{* *}$ \\
Nonverbal play & $1.529(0.678-3.448)$ & .306 & $0.810(0.187-3.505)$ & .778 \\
Younger sibling & $0.589(0.360-0.963)$ & $.035^{*}$ & $0.676(0.330-1.381)$ & .283 \\
Preschool attendance & $0.819(0.459-1.459)$ & .497 & $0.776(0.375-1.607)$ & .494 \\
Living with grandparents & $1.295(0.804-2.086)$ & .288 & $1.030(0.527-2.013)$ & .931 \\
Disease or handicap of twin & & & \\
\hline
\end{tabular}

Note: $\mathrm{OR}=$ odds ratio; $\mathrm{Cl}=$ confidence intervals.

$$
{ }^{*} p<.05 ;{ }^{* *} p<.01 ;{ }^{* * *} p<.001 \text {. }
$$


Lytton, H., Conway, D., \& Sauve, R. (1977). The impact of twinship on parent-child interaction. Journal of Personality and Social Psychology, 35, 97-107.

Luria, A. R., \& Yudovich, F. I. (1966). Speech and the development of mental processes in the child. London: Staples Press.

Mittler, P. (1970). Biological and social aspects of language development in twins. Developmental Medicine and Child Neurology, 12, 741-757.

Ooki, S., Yamada, K., Asaka, A., \& Hayakawa, K. (1990). Zygosity diagnosis of twins by a questionnaire. Acta Geneticae Medicae et Gemellologiae (Roma), 39, 109-115.

Ooki, S., Yamada, K., Asaka, A., Hayakawa, K., \& Shimizu, T. (1989). Zygosity diagnosis of twins by questionnaire. Minzokueisei, 55, 227-235.

Rutter, M., Thorpe, K., Greenwood, R., Northstone, K., \& Golding, J. (2003). Twins as a natural experiment to study the causes of mild language delay. Design: Twin-singleton differences in language, and obstetric risks. Journal of Child Psychology and Psychiatry and Allied Disciplines, 44, 326-341.

Savic, S. (1980). How twins learn to talk: A study of the speech development of twins from 1 to 3 (V. Felbabov, Trans.). London: Academic Press.

Tomasello, M., Mannle, S., \& Kruger, A. C. (1986). Linguistic environment of 1 - to 2 -year-old twins. Developmental Psychology, 22, 169-176.

Thorpe, K., Greenwood, R., Eivers, A., \& Rutter, M. (2001). Prevalence and developmental course of 'secret language'. International Journal of Language 6 Communication Disorders, 36, 43-62.

Thorpe, K., Rutter, M., \& Greenwood, R. (2003). Twins as a natural experiment to study the causes of mild language delay: Family interaction risk factors. Journal of Child Psychology and Psychiatry and Allied Disciplines, 44, 342-355.

\section{Appendix \\ Questionnaire and Coding}

Question

Mother's age

Age of twins at weaning

Length of gestation

Twins' age

Body length at birth

Body height at 18 months

Body weight at birth

Body weight at 18 months

Age at first walking

Age at first tooth

Age at first spoken word

'Is the twin pair as alike as two peas in a pod?'

$\begin{array}{lll}\text { No } & \text { Opposite-sex pairs } & 0 \\ & \text { Male pairs } & 1 \\ \text { Yes } & \text { Female pairs } & 0 \\ & \text { Male pairs } & 0 \\ & \text { Female pairs } & 0\end{array}$

\section{Code}

years old

months

weeks

months

$\mathrm{cm}$
$\mathrm{cm}$
$\mathrm{g}$
$\mathrm{g}$
months
months
months

$\begin{array}{llll}0 & 0 & 0 & 0 \\ 1 & 0 & 0 & 0 \\ 0 & 1 & 0 & 0 \\ 0 & 0 & 1 & 0 \\ 0 & 0 & 0 & 1\end{array}$

'Did the twins have an original language that could not be understood by either their mother or others?'

No 1

Yes

'If yes, was the twin language words or sentences?'

Words

0

Sentences

'Do the twins have a disease or handicap?'

No

0

Yes

'Do you have job?'

No

0

Yes 


\section{Appendix (continued)}

Question

Code

'Did you have morning sickness?'

No

0

Yes

1

'Did you have toxemia of pregnancy?'

No

0

Yes

1

'Does the twin pair show frequent nonverbal play

(e.g., building with blocks, drawing pictures)?'

No

Yes

'Do you live in a detached house or apartment?'

Detached house

Apartment

'Does the twin pair attend preschool?'

No

Yes

'Does the twin pair have neighborhood friends?'

No

Yes

'Does the twin pair have older sibling(s)?'

No

0

Yes

'Does the twin pair have younger sibling(s)?'

No

Yes

'Does the twin pair live with their grandparents?'

No

Yes

1 